\title{
Risperidone and Paliperidone Inhibit P-Glycoprotein Activity In Vitro
}

\author{
Hao-Jie Zhu', Jun-Sheng Wang', John S Markowitz', Jennifer L Donovan², Bryan B Gibson ${ }^{2}$ and \\ C Lindsay DeVane*,2 \\ 'Laboratory of Drug Disposition and Pharmacogenetics, Department of Pharmaceutical Sciences, Medical University of South Carolina, \\ Charleston, SC, USA; '2Laboratory of Drug Disposition and Pharmacogenetics, Department of Psychiatry and Behavioral Sciences, \\ Medical University of South Carolina, Charleston, SC, USA
}

\begin{abstract}
Risperidone (RSP) and its major active metabolite, 9-hydroxy-risperidone (paliperidone, PALI), are substrates of the drug transporter P-glycoprotein (P-gP). The goal of this study was to examine the in vitro effects of RSP and PALI on P-gP-mediated transport. The intracellular accumulation of rhodamine 23 (Rh I23) and doxorubicin (DOX) were examined in LLC-PKI/MDRI cells to evaluate P-gP inhibition by RSP and PALI. Both compounds significantly increased the intracellular accumulation of RhI 23 and DOX in a concentrationdependent manner. The $\mathrm{IC}_{50}$ values of RSP for inhibiting P-gP-mediated transport of RhI23 and DOX were 63.26 and I5.78 $\mu \mathrm{M}$, respectively, whereas the $\mathrm{IC}_{50}$ values of PALI were $>100 \mu \mathrm{M}$, indicating that PALI is a less potent P-gP inhibitor. Caco-2 and primary cultured rat brain microvessel endothelial cells (RBMECs) were utilized to investigate the possible influence of RSP on intestinal absorption and blood-brain barrier (BBB) transport of coadministered drugs that are P-gP substrates. RSP, I-50 $\mu$ M, significantly enhanced the intracellular accumulation of RhI23 in Caco-2 cells by inhibiting P-gp activity with an $\mathrm{IC}_{50}$ value of $5.87 \mu \mathrm{M}$. Following exposure to $10 \mu \mathrm{M}$ RSP, the apparent permeability coefficient of RhI 23 across Caco-2 and RBMECs monolayers was increased to 2.02 and 2.63-fold in the apical to basolateral direction, but decreased to 0.37 and 0.21 -fold in the basolateral to apical direction, respectively. These data suggest that RSP and PALI, to a lesser extent, have a potential to influence the pharmacokinetics and hence the pharmacodynamics of coadministered drugs via inhibition of P-gp-mediated transport. However, no human data exist that address this issue. In particular, RSP may interact with its own active metabolite PALI by promoting its brain concentration through inhibiting P-gp-mediated efflux of PALI across endothelial cells of the BBB.

Neuropsychopharmacology (2007) 32, 757-764. doi: I0.1038/sj.npp. I 30I I8I; published online 23 August 2006
\end{abstract}

Keywords: risperidone; paliperidone; P-glycoprotein; transporter; blood-brain barrier; drug-drug interaction

\section{INTRODUCTION}

P-glycoprotein (ABCB1, MDR1, P-gp) is an ATP-dependent efflux transporter (Ayrton and Morgan, 2001; Mizuno et al, 2003). In addition to its expression in multidrug resistance tumor cells, the distribution of P-gp includes the epithelial cells lining the luminal surface of enterocytes in the small intestine, the canalicular surface of heptocytes, the apical surface of epithelial cells of proximal renal tubules, epithelial cells of placenta on the maternal blood flow side, and the luminal surface of capillary endothelial cells comprising the blood-brain barrier (BBB) (Cordon-Cardo et al, 1989; Lieberman et al, 1989; Fardel et al, 1993;

\footnotetext{
*Correspondence: Dr CL DeVane, Laboratory of Drug Disposition and Pharmacogenetics, Medical University of South Carolina, 173 Ashley Avenue, Room 405B, Charleston, SC 29425, USA, Tel: + I 843792 5448, Fax: + I 843792 6318, E-mail: devaneL@musc.edu

Received 9 February 2006; revised 23 June 2006; accepted I July 2006 Online publication: 12 July 2006 at http:/www.acnp.org/citations/ Npp07|206060082/default.pdf
}

Gatmaitan and Arias, 1993; Bendayan et al, 2002). It is becoming increasingly apparent that P-gp plays an important role in the disposition of numerous structurally diverse drugs that are its substrates (Benet et al, 1999). For example, owing to its active efflux, P-gp limits the intestinal absorption of cyclosporine, ivermectin, and paclitaxel after oral dosing (Sparreboom et al, 1997; Kwei et al, 1999). We and others have shown that P-gp limits the brain penetration in animals of a number of centrally active drugs including risperidone (RSP), its active metabolite 9-hydroxy-resperidone (paliperidone, PALI), methadone, olanzapine, and others (Aquilante et al, 2000; Wang et al, $2004 a, b, c)$. The anatomical localization of P-gp implies it plays a critical role in protecting cells and organs from exposure to xenobiotics. However, P-gp also limits a variety of medications from reaching their therapeutic target(s) thereby preventing or minimizing pharmacological effects. Thus, the status as P-gp substrates of lead compounds in drug development may influence the choice of formulation, route of administration, and dose necessary to achieve 
desired effects (Mizuno et al, 2003). The potential for drugdrug interactions arises when the P-gp substrate is also an inhibitor of P-gp or is coadministered with an inhibitor (Lin, 2003).

RSP is one of the most commonly used atypical antipsychotics. Its major route of elimination is oxidation via hepatic CYP2D6 to 9-hydroxy-risperidone (DeVane and Markowitz, 2000). This active metabolite, also known as paliperidone (PALI), is currently in development as a separate antipsychotic drug (Seeman, 2005). RSP and PALI have similar binding affinities for several receptors thought to be important for antipsychotic efficacy and a favorable adverse event profile (Schotte et al, 1993, 1996). The $K_{\mathrm{i}}$ values for binding to the dopamine $\mathrm{D}_{2}$ and $5 \mathrm{HT}_{2 \mathrm{~A}}$ receptor subtype for RSP and PALI were 5.9 and $4.8 \mathrm{nM}$, and 0.16 and $0.25 \mathrm{nM}$, respectively. However, the off-rate for dissociation from human cloned $\mathrm{D}_{2}$ receptor is faster for PALI $(60 \mathrm{~s})$ compared to RSP (27 min) (Seeman, 2005). By using the P-gp knockout mouse model, we and others have demonstrated that both RSP and PALI are P-gp substrates and their entry into the brain is dramatically limited by P-gp in the BBB (Wang et al, 2004a; Doran et al, 2005). Following intraperitoneal (i.p.) dosing, brain concentrations of RSP and PALI in knockout mice were more than 10 -fold higher than that in wild-type mice, whereas plasma revealed no significant differences in concentrations.

It is well known that some P-gp substrates (eg verapamil, quinidine, etc) are also potent P-gp inhibitors (Sadeque et al, 2000). Coadministration of these inhibitors may result in the alteration of the pharmacokinetics of other drugs that are P-gp substrates (Kharasch et al, 2004; Nakagami et al, 2005). Recent studies have demonstrated that RSP increased the intracellular accumulation of P-gp substrates rhodamine123 (Rh123) and calcein-AM in bovine brain microvessel endothelial cells and MDR1 gene transfected MDCK cells, respectively, indicating that RSP is a potential P-gp inhibitor (Mahar Doan et al, 2002; Bachmeier and Miller, 2005). However, the possible effects of RSP on the disposition of coadministered drugs through P-gp inhibition remain unknown. Our recent study indicated that RSP significantly increased brain concentrations of sertraline and its metabolite desmethylsertraline in a mouse model without significantly altering their plasma concentrations at $1 \mathrm{~h}$ after i.p. injection (Wang et al, 2006a). Based upon a P-gp ATPase activity assay, we have demonstrated that sertraline and desmethylsertraline have high affinity for P-gp indicating that both compounds are potential P-gp substrates (Wang et al, 2006b). Therefore, the increases of sertraline and desmethylsertraline brain concentrations might be caused by the inhibition of P-gp in BBB by RSP.

In this study, the inhibitory effects of RSP and PALI on P-gp activity were investigated utilizing the P-gp overexpressing cell line LLC-PK1/MDR1. Furthermore, the monolayers of Caco-2 and primary cultured rat brain microvessel endothelial cells (RBMECs) served as small intestine and $\mathrm{BBB}$ in vitro models, respectively, to evaluate the possible influence of RSP on the absorption and BBB transport of drugs that are P-gp substrates. This report provides the first data, to our knowledge, documenting the P-gp inhibitory properties of PALI and the potential influence of RSP on the disposition of drugs that are P-gp substrates through P-gp inhibition.

\section{MATERIALS AND METHODS}

\section{Materials}

The pig kidney epithelial cell line LLC-PK1 and its P-gP overexpressing mutant LLC-PK1/MDR1 cells were generously provided by Dr Kari Kivistö (Dr Margarete FischerBosch Institute of Clinical Pharmacology, Stuttgart, Germany). The human colon adenocarcinoma cell line Caco-2 at passage 17 was purchased from American Type Culture Collection (Manassas, VA) and was used for experiments from passages 35 to 45 . Fetal bovine serum and Dulbecco's modified Eagle's medium (DMEM) containing $4500 \mathrm{mg} / \mathrm{l}$ glucose, $4 \mathrm{mM}$ L-glutamine, and sodium pyruvate were purchased from Hyclone Co. (Logan, UT). Collagenase II was obtained from Worthington Biochemical Co. (Lakewood, NJ) and dispase from BD Bioscience (Bedford, MA). MEM nonessential amino acid solution was obtained from Stemcell Technologies Inc. (Vancouver, British Columbia, Canada) whereas trypsin, Dulbecco's phosphate-buffered saline (DPBS), penicillin, and streptomycin were all purchased from Mediatech Inc. (Herndon, VA). Doxorubicin (DOX) and Rh123 were obtained from Sigma Co. (St Louis, MO). RSP and PALI were donated by Janssen Pharmaceutics (Titusville, NJ). Valspodar (PSC833) was a gift from Novartis Pharmaceuticals (Basel, Switzerland). All other drugs and reagents were of analytical grade and commercially available.

\section{Cell Cultures}

LLC-PK1, LLC-PK1/MDR1, and Caco-2 cells. LLC-PK1 and Caco-2 cells were cultured at $37^{\circ} \mathrm{C}$ in DMEM supplemented with $10 \%$ fetal bovine serum, $1 \%$ MEM nonessential amino acids, $100 \mathrm{U} / \mathrm{ml}$ penicillin, and $100 \mu \mathrm{g} / \mathrm{ml}$ streptomycin in an atmosphere of $5 \% \mathrm{CO}_{2}$ and $95 \%$ relative humidity. LLCPK1/MDR1 cells were cultured under the same conditions with the exception of the addition of $640 \mathrm{nM}$ of vincristine which was added to the culture medium to maintain P-gp expression (Smit et al, 1998).

For Rh123 and DOX intracellular accumulation experiments, cells were seeded at a density of $1 \times 10^{5} \mathrm{cells} / \mathrm{ml} / \mathrm{well}$ in 24 -well plates. Culture medium was replaced every 2 days until cells reached confluence.

For transport experiments, Caco-2 cells were seeded onto polyester membrane filters $\left(0.4 \mu \mathrm{m}\right.$ pores, $4.7 \mathrm{~cm}^{2}$ growth area, Corning Inc., Corning, NY) of Transwell inserts at a density of $1 \times 10^{5} \mathrm{cells} / \mathrm{cm}^{2}$. Culture medium was likewise changed every 2 days. Transepithelial electric resistance (TEER) of RBMECs monolayers was monitored before transport studies using an EVOMeter fitted with chopstick electrodes (World Precision Instruments, Sarasota, FL), and the monolayers with TEER of greater than $500 \Omega \mathrm{cm}^{2}$ were utilized for the transport studies.

Primary culture of rat brain microvessel endothelial cells. RBMECs were isolated according to the modified method of Abbott et al (1992). Briefly, the cerebral cortex was obtained from 10-15-day-old rats and washed 3 times with ice-cold DPBS. After surface vessels and meninges were removed, cortex gray matter was minced and incubated at $37^{\circ} \mathrm{C}$ for $1 \mathrm{~h}$ in serum-free DMEM containing $20 \mathrm{U} / \mathrm{ml}$ Dnase I and $0.1 \%$ collagenase II/dispase. After 
digestion, the enzyme mixture was triturated with a Pasteur pipette, then centrifuged at $800 \mathrm{~g}$ for $5 \mathrm{~min}$. The resultant pellet was resuspended in DPBS containing 25\% bovine serum albumin (BSA) and centrifuged at $2000 \mathrm{~g}$ at $4{ }^{\circ} \mathrm{C}$ for $10 \mathrm{~min}$ to remove fat, cell debris, and myelin that were floating on the BSA solution. The pellet containing microvessels was resuspended and incubated in serum-free DMEM containing $0.1 \%$ collagenase II at $37^{\circ} \mathrm{C}$ for $30 \mathrm{~min}$ for a second digestion that served to remove the microvessel basement membrane. Released endothelial cells were further purified by centrifugation over a $50 \%$ Percoll gradient. The cells were maintained in DMEM supplemented with $20 \%$ fetal bovine serum, penicillin $100 \mathrm{kU} / \mathrm{l}$, and streptomycin $100 \mathrm{mg} / \mathrm{l}$.

For transport experiments, RBMECs were applied to polyester transwell membranes $\left(0.4 \mu \mathrm{m}\right.$ pore size; $4.7 \mathrm{~cm}^{2}$ growth area; Corning Inc., Corning, NY) at a density of $1 \times 10^{5} / \mathrm{cm}^{2}$. Culture medium was changed every 3 days. The monolayers with TEER of greater than $250 \Omega \mathrm{cm}^{2}$ were utilized for the transport studies.

\section{Intracellular Rh123 and DOX Accumulation Studies}

Intracellular accumulation of P-gp substrates Rh123 and DOX were measured to evaluate the P-gp activity in LLCPK1/MDR1 and Caco-2 cells whereas LLC-PK1 was included as a negative control (van der Sandt et al, 2000). After reaching confluence, cells were preincubated at $37^{\circ} \mathrm{C}$ for 30 min with transport buffer (serum-free DMEM containing $25 \mathrm{mM} N$-2-hydroxyl piperazine- $N^{\prime}$-2-ehane sulfonic acid, $\mathrm{pH}$ 7.4). Vehicle control (0.5\% dimethylsulfoxide (DMSO)), specific concentrations of RSP, PALI, or PSC833 were added, then $5 \mu \mathrm{M}$ of Rh123 or $10 \mu \mathrm{M}$ of DOX were added for an additional $60 \mathrm{~min}$ incubation. After incubation, the solutions were discarded, and the cells were washed three times with ice-cold DPBS and solubilized with $1 \%$ Triton $\mathrm{X}-100$. The fluorescence of Rh123 and DOX were measured by high-performance liquid chromatography (HPLC) assay. The concentrations were determined from the fluorescence value through the construction of Rh123 and DOX standard curves. The amount of Rh123 or DOX in each sample was standardized with the protein content as determined by the Lowry assay.

\section{Rh123 Transport Studies}

When RBMECs or Caco-2 cells reached confluence, the integrity of monolayers was checked by both TEER value and the transport rate of fluorescein, a recognized paracellular transport marker (van Bree et al, 1988). The qualified monolayers were rinsed two times with DPBS and preincubated with transport buffer at $37^{\circ} \mathrm{C}$ for 30 min. In all, $0.5 \%$ DMSO, RSP, or PSC833 was loaded at both sides of the monolayers, then Rh123 $(5 \mu \mathrm{M})$ was added into the basolateral side for the basolateral to apical (B-A) transport study or apical side for the apical to basolateral (A-B) transport study. At designated times, $150 \mu \mathrm{l}$ samples were taken from the receiver compartment, and the same volume of receiver compartment solution was replaced immediately after each sampling. Concentrations of Rh123 were determined by HPLC. Apparent permeability coefficients, $P_{\text {app }}(\mathrm{cm} / \mathrm{s})$ were calculated according to the following equation:

$$
P_{\text {app }}=\frac{\mathrm{d} Q}{\mathrm{~d} t}\left(C^{-1} A^{-1}\right)
$$

where $\mathrm{dQ} / \mathrm{d} t$ is the rate at which the Rh123 appears in the receiver compartment, $A$ is the diffusion area $\left(\mathrm{cm}^{2}\right)$, and $C$ is the initial concentration of Rh123 in the donor compartment.

\section{HPLC Analysis}

An established HPLC assay was utilized for the quantitative analysis of Rh123 and DOX. The HPLC system consisted of a Waters 2690 Separations module (Waters, Milford, MA), a C18 reversed-phase column $(300 \times 4.1 \mathrm{~mm}$ i.d., Versoack, Alltech, Deerfield, IL), and a Waters 474 scanning fluorescence detector (Waters, Milford, MA). The separation of Rh123 was carried out isocratically using $20 \mathrm{mM}$ of sodium acetate buffer ( $\mathrm{pH} 4.0)$ :acetonitrile $(40: 60, \mathrm{v}: \mathrm{v})$ at a flow rate of $1.0 \mathrm{ml} / \mathrm{min}$. The mobile phase for DOX samples consisted of a $50 \mathrm{mM} \mathrm{NaH} \mathrm{PO}_{4}$ buffer ( $\mathrm{pH} 3.0$ ):acetonitrile (69:31, v:v) mixture with a flow rate of $1.0 \mathrm{ml} / \mathrm{min}$. The detection wavelengths were $488 \mathrm{~nm}(\lambda \mathrm{ex}), 535 \mathrm{~nm}(\lambda \mathrm{em})$ for $\mathrm{Rh} 123$, and $480 \mathrm{~nm}$ ( $\lambda \mathrm{ex}), 560 \mathrm{~nm}(\lambda \mathrm{em})$ for DOX.

\section{Statistical Analysis}

Statistical analysis for significant differences was performed using the two-tailed Student's $t$-test. A $p$-value of 0.05 or less was considered to be statistically significant. Data were calculated as mean $\pm S D$ for display in tables and figures.

\section{RESULTS}

\section{RSP and PALI Increased the Intracellular Accumulation of Rh123 and DOX}

By using Rh123 and DOX exclusion assay, RSP and PALI were evaluated for their potential inhibitory effects on P-gp efflux. Both RSP and PALI significantly increased the intracellular accumulation of Rh123 and DOX in LLC-PK1/MDR1 cells in a concentration-dependent manner (Figure $1 \mathrm{a}$ and $\mathrm{b}$ ). An $\mathrm{IC}_{50}$ value of $63.26 \mu \mathrm{M}$ was obtained for the inhibition of Rh123 efflux by RSP and $15.78 \mu \mathrm{M}$ was recorded for DOX. At concentrations of 50 and $100 \mu \mathrm{M}$, PALI significantly increased the intracellular accumulation of Rh123 and DOX. However, this compound had much lower potency than RSP for inhibiting P-gp efflux activity, and its $\mathrm{IC}_{50}$ values were $>100 \mu \mathrm{M}$ for inhibiting P-gpmediated transport of both Rh123 and DOX. PALI, even at tested concentrations as high as $100 \mu \mathrm{M}$, did not increase substrate accumulation to levels approaching that of the positive control (PSC833 $2 \mu \mathrm{M}$ ) in both Rh123 and DOX accumulation assays. Only when DOX, not Rh123, was used as P-gp substrate, the inhibitory effect of RSP $(100 \mu \mathrm{M})$ was comparable with that of PSC833 $(2 \mu \mathrm{M})$ $(p>0.05)$. With regard to P-gp negative LLC-PK1 cells, neither RSP nor PALI, at concentrations of $100 \mu \mathrm{M}$, had any significant influence on the intracellular accumulation of Rh123 or DOX.

Similar experiments were also conducted to evaluate the inhibitory effect of RSP on P-gp activity in another P-gp 

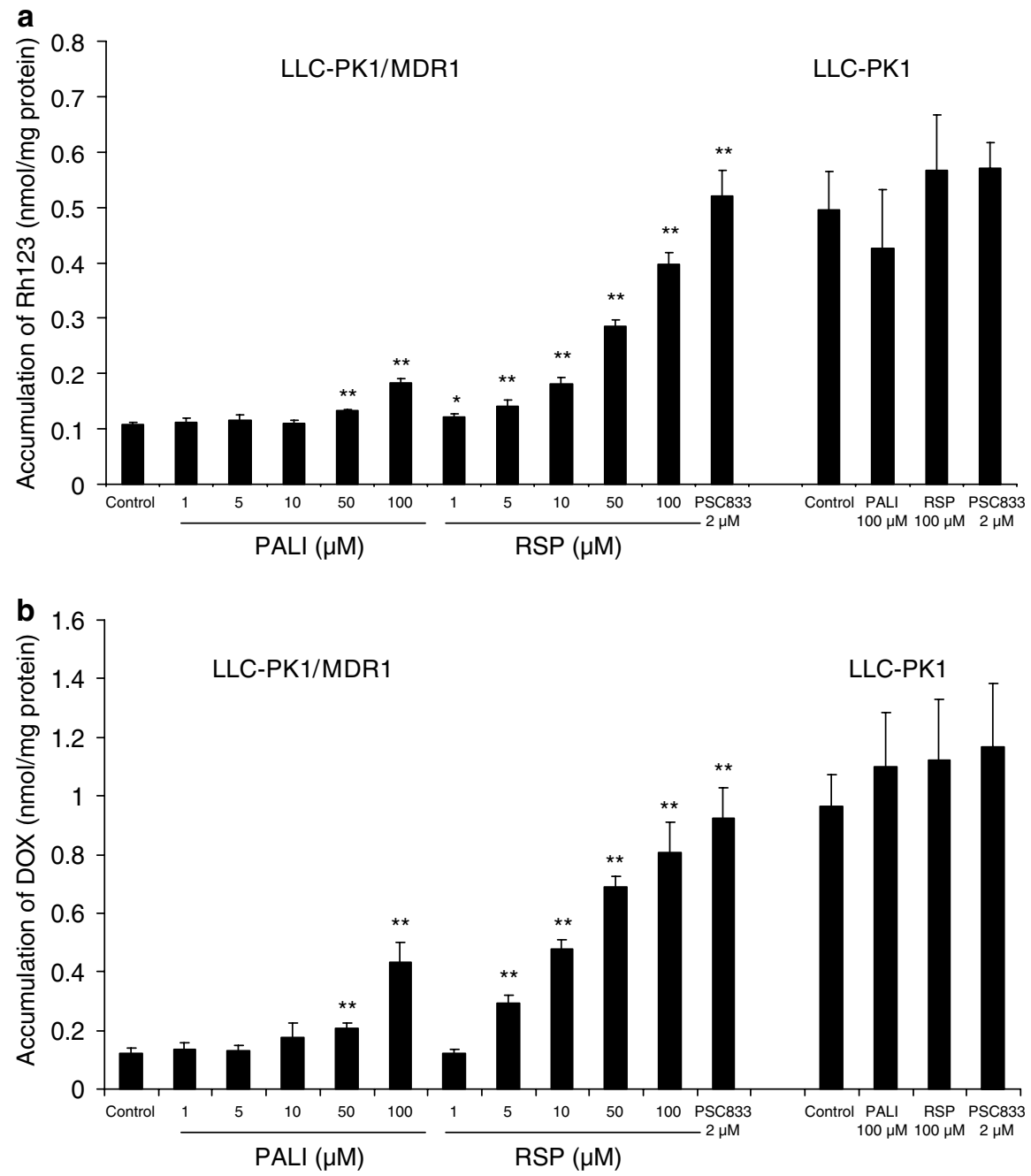

Figure I Effect of RSP and PALI on the intracellular accumulation of RhI23 (a) and DOX (b) in LLC-PKI/MDRI cells. The intracellular accumulation of

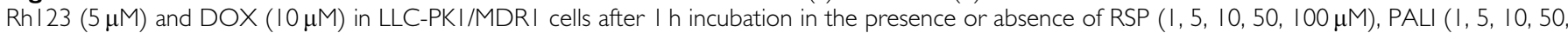
$100 \mu \mathrm{M})$, or PSC833 $(2 \mu \mathrm{M})$ was determined as described in the Materials and Methods section. LLC-PKI cells were also included as the negative control. Each data value is the mean with a bar representing SD, $n=4$. $* p<0.05$ vs control, $* * * 0.0$ I vs control.

expressing cell line, Caco-2 cells. At concentrations ranging from 1 to $50 \mu \mathrm{M}$, RSP significantly enhanced the intracellular accumulation of Rh123 in a concentration-dependent manner through P-gp inhibition with an $\mathrm{IC}_{50}$ value of $5.87 \mu \mathrm{M}$ (Figure 2).

\section{Effect of RSP on the Transport of Rh123 across Caco-2 and RBMECs Monolayers}

Caco-2 and RBMECs monolayers were utilized in this study as in vitro models to investigate the influence of RSP on intestinal absorption and BBB entry of P-gp substrate, respectively. As shown in Table 1, Rh123 exhibited highly polarized transport across Caco-2 and RBMECs monolayers (ie $P_{\text {app B-A }} \gg P_{\text {app A-B }}$ ). In the presence of $10 \mu \mathrm{M}$ of RSP, the transport of Rh123 was significantly decreased in the B-A direction but increased in the A-B direction in both Caco-2 and RBMECs monolayers (Figures 3 and 4). In Caco-2 cells, the $P_{\text {app }}$ value was decreased by $62.9 \%$ in the $\mathrm{B}-\mathrm{A}$ direction and increased by $102.2 \%$ in the A-B direction in the presence of $10 \mu \mathrm{M}$ RSP. Regarding RBMECs, the treatment

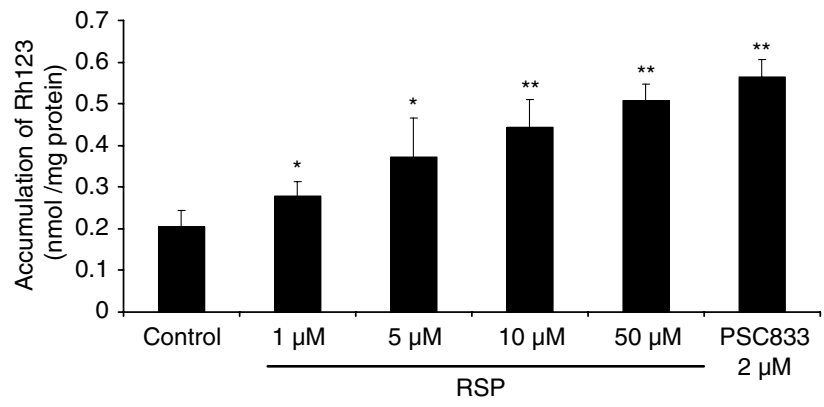

Figure 2 Effect of RSP on the intracellular accumulation of Rh123 in Caco-2 cells. Inhibitory effect of RSP on P-gp function in Caco-2 cells was assessed by measuring the intracellular concentrations of Rh/23 after incubation for I $\mathrm{h}$ in the absence or presence of $\operatorname{RSP}(1,5,10,50 \mu \mathrm{M})$. Each data value is the mean with a bar representing $S D, n=4$. ${ }^{*} p<0.05$ vs control, $* * * 0.0$ I vs control.

of $10 \mu \mathrm{M}$ of RSP resulted in a $79.3 \%$ decrease of Rh123 $P_{\text {app B-A }}$ value and $162.5 \%$ increase of Rh123 $P_{\text {app A-B }}$ value. The positive control (PSC833, $2 \mu \mathrm{M})$ produced a similar 

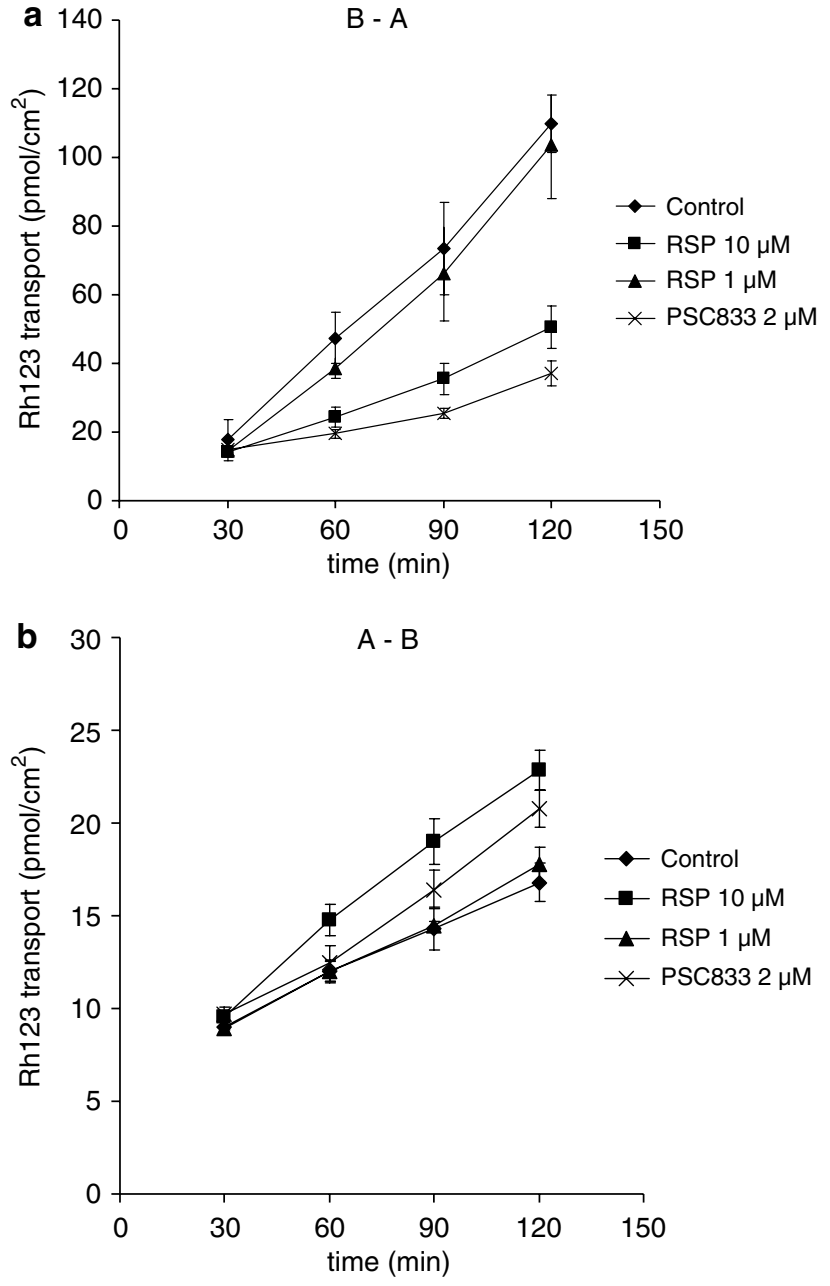

Figure 3 Effect of RSP on the directional transport of Rh 123 across Caco-2 cell monolayers. RhI23 (5 $\mathrm{M}$ ) was added to the basolateral (for B-A transport, a) or apical side (for A-B transport, b) of Caco-2 cell monolayers, whereas RSP $(\mathrm{I}, 10 \mu \mathrm{M})$ or PSC833 $(2 \mu \mathrm{M})$ was added to both sides of monolayers. The amounts of Rh 123 in the receiver compartment were determined at 30, 60, 90, 120 min after incubation. Each point represents the mean $\pm S D$ of three experiments.

Table I Effect of RSP on Apparent Permeability Coefficients $\left(P_{\text {app }}\right)$ of Rh 123 (5 $\left.\mu \mathrm{M}\right)$ across Caco-2 Cells and RBMECs Monolayers

\begin{tabular}{|c|c|c|c|c|}
\hline \multirow[b]{2}{*}{ Cell } & \multirow[b]{2}{*}{ Inhibitor } & \multicolumn{2}{|c|}{$P_{\text {app }}\left(\mathrm{cm} \mathrm{s}^{-1} \times 10^{-7}\right)$} & \multirow{2}{*}{$\begin{array}{c}\text { Ratio } \\
\text { (Papp B-A } / \\
\left.P_{\text {app A-B }}\right)\end{array}$} \\
\hline & & B-A & A-B & \\
\hline \multirow[t]{4}{*}{ Caco-2 } & Control & $18.68 \pm 0.78$ & $1.80 \pm 0.34$ & 10.38 \\
\hline & I $\mu \mathrm{M}$ RSP & $|8.34 \pm 3.4|$ & $2.19 \pm 0.31$ & 8.37 \\
\hline & $10 \mu \mathrm{M}$ RSP & $6.93 \pm 0.94 * * *$ & $3.64 \pm 0.41^{* * * *}$ & 1.90 \\
\hline & $2 \mu \mathrm{M}$ PSC833 & $3.91 \pm 0.85 * *$ & $2.96 \pm 0.22 * *$ & 1.32 \\
\hline \multirow[t]{3}{*}{ RBMECs } & Control & $35.04 \pm 4.39$ & $1.20 \pm 0.06$ & 29.20 \\
\hline & $10 \mu \mathrm{M}$ RSP & $7.26 \pm 0.58^{* * *}$ & $3.15 \pm 0.25 * *$ & 2.30 \\
\hline & $2 \mu \mathrm{M}$ PSC833 & $9.74 \pm 0.42 * * *$ & $2.97 \pm 0.33^{*} *$ & 3.28 \\
\hline
\end{tabular}

Results are reported as mean $\pm \mathrm{SD}, n=3$.

*** $p<0.0$ I vs control.
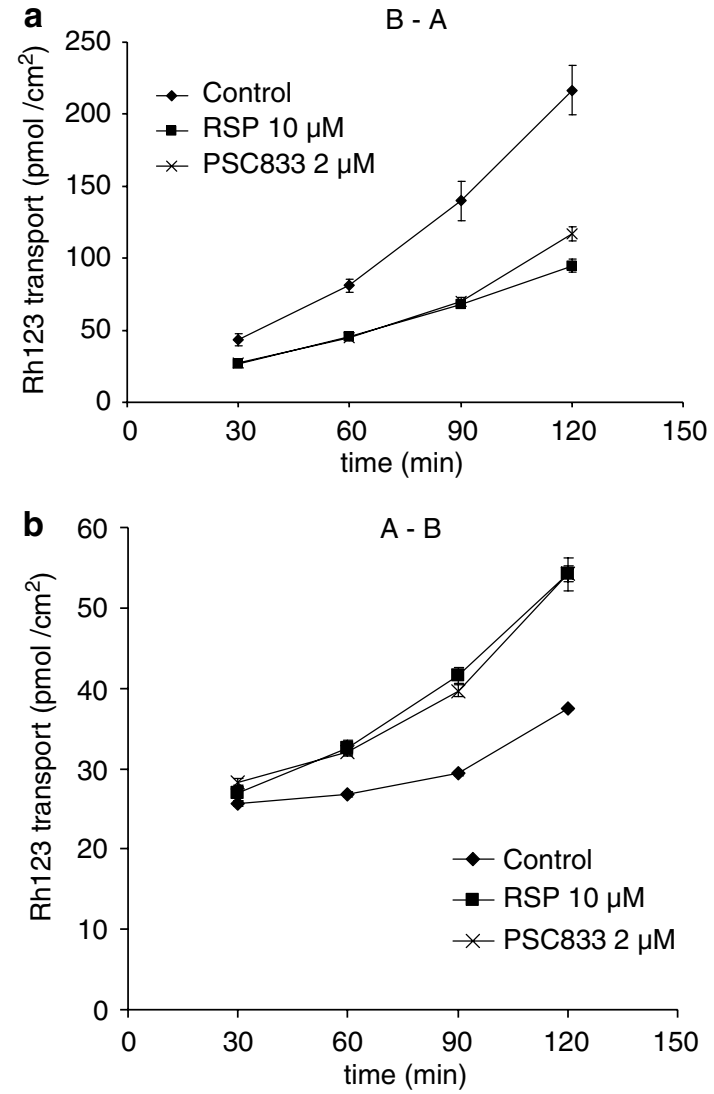

Figure 4 Effect of RSP on the directional transport of Rh 123 across the RBMECs monolayers. RhI23 (5 $\mu \mathrm{M})$ was added to the donor compartment, whereas RSP $(10 \mu \mathrm{M})$ or PSC833 $(2 \mu \mathrm{M})$ was added to both the apical and basolateral compartment. After 30, 60, 90, 120 min incubation, concentration of Rh 123 in receiver compartment was determined to assess Rh123 transport in both B-A (a) and A-B (b) directions. Each point represents the mean with a bar representing SD of three experiments.

effect on P-gp-mediated Rh123 transport across Caco-2 and RBMECs monolayers. In the A-B direction, $10 \mu \mathrm{M}$ RSP

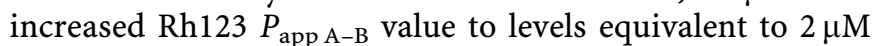
PSC833 in both Caco-2 and RBMECs monolyers $(p>0.05)$. In the B-A direction, $10 \mu \mathrm{M}$ RSP exhibited a significantly higher effect in decreasing Rh123 transport across RBMECs monolyers than $2 \mu \mathrm{M}$ PSC833 $(p<0.05)$, but less across Caco-2 monolyers $(p<0.05)$.

\section{DISCUSSION}

A previous in vitro study by our group using an ATPase activity assay provided some of first evidence that several atypical antipsychotic drugs, that is, quetiapine, olanzapine, and RSP, exhibited high affinity for P-gp (Boulton et al, 2002). Subsequent in vivo studies in P-gp knockout mouse models by our group and others revealed that brain concentration, and ratio of brain-to-plasma concentrations of RSP and its major metabolite, PALI, were significantly higher in knockout mice $v s$ wild-type animals (Wang et al, 2004a; Doran et al, 2005). These results indicated that both RSP and PALI are substrates of P-gp and that their disposition might be influenced by the functional 
status of P-gp. Furthermore, RSP has been reported to be a potential P-gp inhibitor by increasing the intracellular accumulation of the P-gp substrates Rh123 and calceinAM in bovine brain microvessel endothelial cells and MDCKII-MDR1 cells, respectively (Mahar Doan et al, 2002; Bachmeier and Miller, 2005). This possibility also offers the unique opportunity for RSP to influence the brain accumulation of PALI when the latter compound is formed in vivo from RSP administration than in comparison to separate administration as a pre-formed metabolite alone. No published data are available on the status of PALI as a P-gp inhibitor.

In our current study, the MDR1 gene transfected cell line LLC-PK1/MDR1 was used to evaluate the inhibitory effect of both RSP and PALI on P-gp activity. The parental cell line LLC-PK1 was included as a negative control. The results demonstrated that both RSP and PALI increased the intracellular accumulation of Rh123 and DOX in LLCPK1/MDR1 cells in a concentration-dependent manner, with RSP exhibiting a much higher potency than PALI. The increments of Rh123 and DOX caused by $100 \mu \mathrm{M}$ RSP were 3.8 and 2.2-fold higher, respectively, than that caused by $100 \mu \mathrm{M}$ of PALI. As a comparison, in P-gp-negative LLCPK1 cells, both RSP and PALI did not alter the intracellular accumulation of Rh123 and DOX. As P-gp expression is generally viewed as the only functional difference between LLC-PK1 and LLC-PK1/MDR1 cells, these data suggest that the mechanism by which RSP and PALI increased Rh123 and DOX intracellular accumulation is through inhibition of P-gp-mediated efflux. Owing to the relatively weak inhibitory effects observed with PALI, further experiments using Caco-2 and RBMECs models were only conducted with RSP.

The intestinal epithelial cell line Caco-2 is one of the most commonly used in vitro models for prediction of intestinal drug absorption. A variety of transporters including P-gp are functionally expressed in Caco-2 cells (Hunter et al, 1993). Co-administration of RSP at concentrations from 1 to $50 \mu \mathrm{M}$ with Rh123 resulted in significant increases of the intracellular accumulation of Rh123 in a concentrationdependent manner. Owing to the apical localization and directional transport of P-gp in Caco-2 monolayers, the $P_{\text {app }}$ value of Rh123 in the B-A direction was approximately 10 fold of that in the A-B direction under our experimental conditions. This effect of RSP on the transport of Rh123 across Caco-2 monolayers is in agreement with its P-gp inhibitory activity. The transport of Rh123 was significantly decreased in $\mathrm{B}-\mathrm{A}$ direction, but increased in $\mathrm{A}-\mathrm{B}$ direction by the coadministration of $10 \mu \mathrm{M}$ RSP.

To date, several cell culture systems have been established as in vitro BBB model (Terasaki et al, 2003). Given the localized expression of P-gp, primary cultured brain microvessel endothelial cells have been widely used for the investigation of P-gp-mediated transport across BBB (Loscher and Potschka, 2005). In this study, the potential influence of RSP on the P-gp-mediated drug transport through $\mathrm{BBB}$ was evaluated using primary cultured RBMECs monolayers. The results indicated that $10 \mu \mathrm{M}$ of RSP significantly inhibited P-gp efflux and decreased Rh123 transport in the $\mathrm{B}-\mathrm{A}$ direction but increased transport in the reverse direction, a finding consistent with the observations in the Caco-2 monolayers experiment previously discussed.
As more therapeutic agents have been demonstrated to be P-gp substrates and/or inhibitors, there is increasing evidence for P-gp-mediated drug-drug interactions (Balayssac et al, 2005). It is well known that the intestinal absorption and brain entry of xenobiotics that are P-gp substrates can be significantly enhanced by the coadministration of P-gp inhibitors such as PSC833, GF120918 and verapamil (Mayer et al, 1997; Bardelmeijer et al, 2000; Nakagami et al, 2005). One issue of concern when attempting to evaluate the possible influence of a P-gp inhibitor on the disposition of a coadministered drug is its inhibitory potency, along with the local concentration achieved by the putative P-gp inhibitor. According to our results of the intracellular Rh123 accumulation in LLC-PK1/ MDR1 cells, RSP and PALI showed significantly inhibitory effects on P-gp activity at and above the concentrations of 1 and $50 \mu \mathrm{M}$, respectively. After oral administration at typical therapeutic doses in rats, the mean peak plasma concentrations of both RSP and PALI were approximately $0.4 \mu \mathrm{M}$ (Aravagiri et al, 1998). Therefore, RSP, rather than PALI, may be more likely to affect the disposition of coadministered P-gp substrates.

It is recognized that P-gp is highly expressed in the liver and kidney. Sufficient inhibition of P-gp function can result in the delay of hepatic and renal clearance of P-gp substrates (Slapak et al, 2001; Pinto et al, 2005). The ratio of liver and kidney to plasma concentration of RSP was 22.3 and 14.3, whereas that of PALI was 67.5 and 47.1, respectively, in an animal model (Aravagiri and Marder, 2002). This significant tissue accumulation suggests that RSP and PALI may influence the pharmacokinetics of P-gp substrates through inhibition of P-gp in the liver and kidney. This issue has not yet been addressed in human studies.

The influence of a P-gp inhibitor on P-gp function within the $\mathrm{BBB}$ is a consequence of the inhibitor's potency, its plasma concentration, and its accumulation in BMECs, which form the BBB. Considering the relatively low plasma concentration of RSP, it is difficult to determine from the present experiments whether RSP could exhibit an inhibitory effect on P-gp within the BBB under usual clinical circumstances. Interestingly, our recent investigations have indicated that RSP significantly increased brain concentrations of the antidepressant sertraline and its principal metabolite desmethylsertraline in mice without altering their plasma concentrations at $1 \mathrm{~h}$ after i.p. injection (Wang et al, 2006a). Sertraline and desmethylsertraline have previously been reported to be P-gp inhibitors (Weiss et al, 2003). In addition, based upon a P-gp ATPase activity assay, our recent study indicated that sertraline and desmethylsertraline had high affinity for P-gp (Wang et al, 2006b). The $V_{\max } / K_{\mathrm{m}}$ values of sertraline (1.6) and desmethylsertraline (1.4) were comparable with that of the positive control P-gp substrate verapamil (1.7) indicating both compounds are potential P-gp substrates. It would be a reasonable assumption that the increases of sertraline and desmethylsertraline concentrations within the brain are the result of inhibition of P-gp in BBB after coadministration of RSP. Although our data demonstrated that both RSP and PALI are P-gp inhibitors in vitro, the clinical relevance of P-gp inhibition by RSP and PALI remains to be determined because of the lack of clinical data on P-gp-mediated drug 
interactions in humans involving RSP and PALI, and the intrinsic limitation of the relevance in vitro and animal experiments.

Of considerable theoretical interest is whether RSP, as a P-gp inhibitor, has an effect on the brain entry of its principal active metabolite and P-gp substrate PALI. Our previous work showed that the increase of brain-to-plasma ratio of PALI compared to RSP was greater in P-gp knockout mice than control mice (Wang et al, 2004a). Although both these compounds are P-gp substrates, the added capability of RSP to inhibit P-gp at the level of the $\mathrm{BBB}$ suggests a potential for enhancing the entry of PALI into the central nervous system when PALI is formed following the oral administration of RSP. Such an effect would not be present if PALI was administered as a preformed metabolite in the absence of RSP. Recognition of such relationships between drugs and their metabolites may help design studies to determine effective doses and explain observed differences in pharmacokinetic or pharmacodynamic effects between metabolites formed systemically or developed as separate therapeutic agents.

The mechanistic basis of P-gp transport and inhibition has been intensively studied for many years. Several hypotheses have been developed in an effort to explain the molecular mechanism of interaction of P-gp and its substrates or inhibitors. However, owing to multiple drug binding sites on P-gp, the development of a universally accepted model for reconciling the data from various laboratories remains a challenge. It has been demonstrated that there is a minimum of four drug binding sites on P-gp. These sites can be divided into two categories: transport sites, at which translocation of drug across the cellular membrane can occur, and regulatory sites, which modify P-gp function (Martin et al, 2000). In addition, some agents can inhibit P-gp activity by decreasing intracellular ATP supply and inhibiting P-gp ATPase activity (Batrakova et al, 2001). Considering the fact that both RSP and PALI appear to be P-gp substrates as well as inhibitors, competition with other substrates for binding to $\mathrm{P}$-gp is a possible mechanism of their P-gp inhibition. However, other mechanisms cannot be excluded and further studies are needed to elucidate the molecular basis of RSP and PALI interactions with P-gp.

\section{ACKNOWLEDGEMENTS}

This work was supported by NIH grant MH071811-02A1.

\section{REFERENCES}

Abbott NJ, Hughes CC, Revest PA, Greenwood J (1992). Development and characterisation of a rat brain capillary endothelial culture: towards an in vitro blood-brain barrier. J Cell Sci 103(Part 1): 23-37.

Aquilante CL, Letrent SP, Pollack GM, Brouwer KL (2000). Increased brain P-glycoprotein in morphine tolerant rats. Life Sci 66: PL47-PL51.

Aravagiri M, Marder SR (2002). Brain, plasma and tissue pharmacokinetics of risperidone and 9-hydroxyrisperidone after separate oral administration to rats. Psychopharmacology (Berlin) 159: 424-431.

Aravagiri M, Marder SR, Wirshing D, Wirshing WC (1998). Plasma concentrations of risperidone and its 9-hydroxy metabolite and their relationship to dose in schizophrenic patients: simultaneous determination by a high performance liquid chromatography with electrochemical detection. Pharmacopsychiatry 31: 102-109.

Ayrton A, Morgan P (2001). Role of transport proteins in drug absorption, distribution and excretion. Xenobiotica 31: 469-497.

Bachmeier CJ, Miller DW (2005). A fluorometric screening assay for drug efflux transporter activity in the blood-brain barrier. Pharm Res 22: 113-121.

Balayssac D, Authier N, Cayre A, Coudore F (2005). Does inhibition of P-glycoprotein lead to drug-drug interactions? Toxicol Lett 156: 319-329.

Bardelmeijer HA, Beijnen JH, Brouwer KR, Rosing H, Nooijen WJ, Schellens JH et al (2000). Increased oral bioavailability of paclitaxel by GF120918 in mice through selective modulation of P-glycoprotein. Clin Cancer Res 6: 4416-4421.

Batrakova EV, Li S, Vinogradov SV, Alakhov VY, Miller DW, Kabanov AV (2001). Mechanism of pluronic effect on Pglycoprotein efflux system in blood-brain barrier: contributions of energy depletion and membrane fluidization. J Pharmacol Exp Ther 299: 483-493.

Bendayan R, Lee G, Bendayan M (2002). Functional expression and localization of P-glycoprotein at the blood brain barrier. Microsc Res Tech 57: 365-380.

Benet LZ, Izumi T, Zhang Y, Silverman JA, Wacher VJ (1999). Intestinal MDR transport proteins and P-450 enzymes as barriers to oral drug delivery. J Control Release 62: 25-31.

Boulton DW, DeVane CL, Liston HL, Markowitz JS (2002). In vitro P-glycoprotein affinity for atypical and conventional antipsychotics. Life Sci 71: 163-169.

Cordon-Cardo C, O'Brien JP, Casals D, Rittman-Grauer L, Biedler JL, Melamed MR et al (1989). Multidrug-resistance gene (Pglycoprotein) is expressed by endothelial cells at blood-brain barrier sites. Proc Natl Acad Sci USA 86: 695-698.

DeVane CL, Markowitz JS (2000). Drugs as substrates of metabolic enzymes: antipsychotics. In: Levy RH, Thummel KE, Trager WF, Hansten PD, Eichelbaum M (eds). Metabolic Drug Interactions. Lippincott-Raven Press: Philadelphia, PA. pp 245-258.

Doran A, Obach RS, Smith BJ, Hosea NA, Becker S, Callegari E et al (2005). The impact of P-glycoprotein on the disposition of drugs targeted for indications of the central nervous system: evaluation using the MDR1A/1B knockout mouse model. Drug Metab Dispos 33: 165-174.

Fardel O, Morel F, Guillouzo A (1993). P-glycoprotein expression in human, mouse, hamster and rat hepatocytes in primary culture. Carcinogenesis 14: 781-783.

Gatmaitan ZC, Arias IM (1993). Structure and function of Pglycoprotein in normal liver and small intestine. Adv Pharmacol 24: 77-97.

Hunter J, Jepson MA, Tsuruo T, Simmons NL, Hirst BH (1993). Functional expression of P-glycoprotein in apical membranes of human intestinal Caco-2 cells. Kinetics of vinblastine secretion and interaction with modulators. J Biol Chem 268: 14991-14997.

Kharasch ED, Hoffer C, Whittington D (2004). The effect of quinidine, used as a probe for the involvement of P-glycoprotein, on the intestinal absorption and pharmacodynamics of methadone. Br J Clin Pharmacol 57: 600-610.

Kwei GY, Alvaro RF, Chen Q, Jenkins HJ, Hop CE, Keohane CA et al (1999). Disposition of ivermectin and cyclosporin A in CF-1 mice deficient in mdrla P-glycoprotein. Drug Metab Dispos 27: 581-587.

Lieberman DM, Reithmeier RA, Ling V, Charuk JH, Goldberg H, Skorecki KL (1989). Identification of P-glycoprotein in renal brush border membranes. Biochem Biophys Res Commun 162: 244-252.

Lin JH (2003). Drug-drug interaction mediated by inhibition and induction of P-glycoprotein. Adv Drug Deliv Rev 55: 53-81. 
Loscher W, Potschka H (2005). Role of drug efflux transporters in the brain for drug disposition and treatment of brain diseases. Prog Neurobiol 76: 22-76.

Mahar Doan KM, Humphreys JE, Webster LO, Wring SA, Shampine LJ, Serabjit-Singh CJ et al (2002). Passive permeability and P-glycoprotein-mediated efflux differentiate central nervous system (CNS) and non-CNS marketed drugs. J Pharmacol Exp Ther 303: 1029-1037.

Martin C, Berridge G, Higgins CF, Mistry P, Charlton P, Callaghan $\mathrm{R}$ (2000). Communication between multiple drug binding sites on P-glycoprotein. Mol Pharmacol 58: 624-632.

Mayer U, Wagenaar E, Dorobek B, Beijnen JH, Borst P, Schinkel AH (1997). Full blockade of intestinal P-glycoprotein and extensive inhibition of blood-brain barrier P-glycoprotein by oral treatment of mice with PSC833. J Clin Invest 100: 2430-2436.

Mizuno N, Niwa T, Yotsumoto Y, Sugiyama Y (2003). Impact of drug transporter studies on drug discovery and development. Pharmacol Rev 55: 425-461.

Nakagami T, Yasui-Furukori N, Saito M, Tateishi T, Kaneo S (2005). Effect of verapamil on pharmacokinetics and pharmacodynamics of risperidone: in vivo evidence of involvement of P-glycoprotein in risperidone disposition. Clin Pharmacol Ther 78: $43-51$.

Pinto N, Halachmi N, Verjee Z, Woodland C, Klein J, Koren G (2005). Ontogeny of renal P-glycoprotein expression in mice: correlation with digoxin renal clearance. Pediatr Res 58: 1284-1289.

Sadeque AJ, Wandel C, He H, Shah S, Wood AJ (2000). Increased drug delivery to the brain by P-glycoprotein inhibition. Clin Pharmacol Ther 68: 231-237.

Schotte A, Janssen PF, Gommeren W, Luyten WH, Van Gompel P, Lesage AS et al (1996). Risperidone compared with new and reference antipsychotic drugs: in vitro and in vivo receptor binding. Psychopharmacology (Berlin) 124: 57-73.

Schotte A, Janssen PF, Megens AA, Leysen JE (1993). Occupancy of central neurotransmitter receptors by risperidone, clozapine and haloperidol, measured ex vivo by quantitative autoradiography. Brain Res 631: 191-202.

Seeman P (2005). An update of fast-off dopamine D2 atypical antipsychotics. Am J Psychiatry 162: 1984-1985.

Slapak CA, Dahlheimer J, Piwnica-Worms D (2001). Reversal of multidrug resistance with LY335979: functional analysis of P-glycoprotein-mediated transport activity and its modulation in vivo. J Clin Pharmacol 41(Suppl): 29S-38S.
Smit JW, Weert B, Schinkel AH, Meijer DK (1998). Heterologous expression of various P-glycoproteins in polarized epithelial cells induces directional transport of small (type 1) and bulky (type 2) cationic drugs. J Pharmacol Exp Ther 286: 321-327.

Sparreboom A, van Asperen J, Mayer U, Schinkel AH, Smit JW, Meijer DK et al (1997). Limited oral bioavailability and active epithelial excretion of paclitaxel (Taxol) caused by P-glycoprotein in the intestine. Proc Natl Acad Sci USA 94: 2031-2035.

Terasaki T, Ohtsuki S, Hori S, Takanaga H, Nakashima E, Hosoya $\mathrm{K}$ (2003). New approaches to in vitro models of blood-brain barrier drug transport. Drug Discov Today 8: 944-954.

van Bree JB, de Boer AG, Danhof M, Ginsel LA, Breimer DD (1988). Characterization of an 'in vitro' blood-brain barrier: effects of molecular size and lipophilicity on cerebrovascular endothelial transport rates of drugs. J Pharmacol Exp Ther 247: 1233-1239.

van der Sandt IC, Blom-Roosemalen MC, de Boer AG, Breimer DD (2000). Specificity of doxorubicin versus rhodamine-123 in assessing P-glycoprotein functionality in the LLC-PK1, LLCPK1:MDR1 and Caco-2 cell lines. Eur J Pharm Sci 11: 207-214.

Wang JS, DeVane CL, Gibson BB, Donovan JL, Markowitz JS, Zhu HJ (2006a). Population pharmacokinetic analysis of drug-drug interactions among risperidone, bupropion, and sertraline in CF1 mice. Psychopharmacology (Berlin) 183: 490-499.

Wang JS, Ruan Y, Taylor RM, Donovan JL, Markowitz JS, DeVane CL (2004a). The brain entry of risperidone and 9-hydroxyrisperidone is greatly limited by P-glycoprotein. Int J Neuropsychopharmacol 7: 415-419.

Wang JS, Ruan Y, Taylor RM, Donovan JL, Markowitz JS, DeVane CL (2004b). Brain penetration of methadone (R)- and (S)enantiomers is greatly increased by P-glycoprotein deficiency in the blood-brain barrier of Abcbla gene knockout mice. Psychopharmacology (Berlin) 173: 132-138.

Wang JS, Taylor R, Ruan Y, Donovan JL, Markowitz JS, Lindsay De Vane C (2004c). Olanzapine penetration into brain is greater in transgenic Abcbla P-glycoprotein-deficient mice than FVB1 (wild-type) animals. Neuropsychopharmacology 29: 551-557.

Wang JS, Zhu HJ, Gibson BB, Donovan JL, Markowitz JS, DeVane CL (2006b). Sertraline and its metabolite desmethylsertraline, but not bupropion or its major metabolite, have high affinity for P-glycoprotein. Clin Pharmacol Ther 79: P16.

Weiss J, Dormann SM, Martin-Facklam M, Kerpen CJ, KetabiKiyanvash N, Haefeli WE (2003). Inhibition of P-glycoprotein by newer antidepressants. J Pharmacol Exp Ther 305: 197-204. 